\title{
How to Construct Digital Libraries in the Information Age
}

\author{
Gemin Li \\ Jilin Agricultural University Library \\ Jilin, China, 130118
}

\begin{abstract}
The construction of digital library is an important part of national information infrastructure, which is the important strategy of the library in the 21 st century to meet the Internet age. Although traditional library won't disappear in the 21 st century, the popularity of electronic publications, digital library will be in the lead. Future library will be to serve the technology characteristics and theory that can quickly possess of information resources and provide information products to the society. The digital library will be the most important symbol of the information ability, therefore, it will have more meanings of our age.
\end{abstract}

Keywords—digital library; meaning; construction

\section{INTRODUCTION}

At present time, energy and information technology are having fast development, so that traditional library collection and transmission methods are having significant changes. With the help of constantly updated modern information technology, field of information is undergoing a revolution, where a new stage of the development for the libraries aiming to fulfill the development of their literature resources and the digital networks is in full swing.

\section{THE BASIC CONCEPT OF DIGITAL LIBRARY}

The origin of the digital library's can earliest date back to the start of the electronic library that was brought out and formally issued by Woolf in his white paper of international cooperation in 1988, who was from the National Science Foundation. Because computer science, technology and information technology have been constantly improved, both the theoretical and practical concepts of digital library are becoming ripe. China's first digital libraries started in the mid -1990 , which, for the most part, are having rapid development.

Domestically and internationally, a large number of famous library experts and scholars from the field of literature information discipline universally deem the advanced stage of library automation, which the American Digital Library Alliance stated as an organization of professional and related resources and digital resources selection. The digital library provides intelligent access, translation, communication and maintains their integrity and permanence, etc, where these digital resources can be quickly and economically used by a particular user or group.
The Information infrastructure technology and application team of the U.S government pointed out in a report that: digital libraries' most important functions are to provide the key information management technology for the national information infrastructure and at the same time, the main database and repository which we can describe as the core of the national information infrastructure. The distribution and large-scale and organization of database and knowledge base makes digital libraries big systematic unit, from where user or user group will have the access to the database and knowledge to get the useful information they need. Although people from home and abroad don't have one same definition of what digital libraries are, for the basic part, they have understand the digital libraries in almost the same way $^{[1]}$.

People will usually agree upon digital libraries from the following four basic characteristic: first, the comprehensive computerization of library management; second, the digitization and the ability to organize the digital information library collection resources; third, having network links to other digital library and being capable of providing the online retrieval and consulting services; fourth, resources sharing. The most important function of the digital library is to digitize the existing entity of a library such as books and all kinds of audio and video data, and traditional literature information ${ }^{[2]}$, which will help users to get information they need via the network, and the other function is to order the existing digital resources and library collection as to finally share the knowledge of the human resources with all the users.

\section{SOME PROBLEMS OF DigitAl LIBRARY CONSTRUCTION IN CHINA}

\section{A. Inadequate Understanding of Digital Libraries and System Construction}

China started to have theoretical study and construction of digital libraries from 2001, but along with the history, it has been basically staying at the groping stage. Our country hasn't come into a stage of large-scale, practical and real development until 2001. Fortunately, our country's digital libraries are being warmly welcomed in recent years, but there is still some immature understanding of what digital library is - a lot of people understand digital libraries as simply digitalization of books and materials, actually, 
however, real digital libraries are a systematic and wide range project not simply scanning books and materials into computers. Digital libraries shouldn't be digital libraries alone, but they should be the culture media, where a platform of cultural product of the network business, of the basis of the national organization, development and utilization of digital resources, and the collection and distribution center of network cultural is formed so as to be the core of national digital resource.

\section{B. How to Improve the Quality of Digital Library Staff}

Library staff's quality is the key factor to development and what makes sure the normal order of the digital libraries, which requires the staff's traditional theory of library science, information science and technology. Moreover, we should pay attention to the basic theory of modern technology and the practical skills and the ability to use computer and network, in order to meet the demands of digital library hardware management and network maintenance. Library staff's foreign language ability is the next time to ponder. Because of the Internet's hefty foreign language information, library staff must also have the ability to complete network service work in the new period, as well as some knowledge of property rights (copyright) protection, network security, etc. Besides the requirement for library staff, the users' quality needs improving, too. Digital libraries give their users higher request_— Some users can skillfully operate on the computers which ensures them to obtain all kinds of information through the network, but others, due to limited education, fall behind in requirements of the digital libraries, which means that they cannot control the computer skilled, they do not have the keen information consciousness, or they cannot use the computer in information retrieval.

\section{Digital Library Construction's Technology Problems}

The problem mainly comes from the technology of document storage and compression. Digital libraries are facing various kinds of and vast amounts of data, then it is one of the core tasks of system design to save and manage huge amounts of data. For there isn't a universal standard classification, indexing and retrieval technology for digital libraries, the users will face the sea of knowledge, finding it hard to obtain the knowledge, and their information retrieval is like a needle in a haystack, which brings up a hard question. The server terminal scheduling technology: Export bandwidth is not wide and fast enough.

The last but not the least, the choices of tools and operation system: This is biggest challenges that digital library must face, for it includes overall structure standards, software and hardware technology, the information input tool, search tools and knowledge mining tools ${ }^{[3]}$.

\section{Network Information Security Problems}

Computer virus is toughest enemy threatening network information safety. And an internet intruder is difficult to be found because of the network's encryption and anonymityA lot of hacker do not do intruding only for economic benefit, but self-challenge is another driving force. The third is the stealing spying, who peeps confidential information to reproduce or diffusion. And the fourth is intentional damage, destroy or damage information processing function of the system electronic communications devices. And these problems tend to make data lost, had been stolen ${ }^{[4]}$ distortion, or damaged, thus affecting the security of online information service.

\section{E. Copyright Conflicts Incapable of Getting Better Solution}

The core of the digital library is the information repository, which contains collecting and sorting out of the basic work, and it will involve the use of digital works and the authorization of the copyright problem. According to the present copyright law of our country, the "fair use" of books is only restricted to need of displaying so as to protect the rare version to copy the library collection of works and books. Clearly, the library digitalization of works is beyond the "fair use" category. At present, the construction of digital library is not a simple transformation of the traditional library's collection or literature. Its function should aim at transforming into digital information platform, which fulfills the network environment of digital library as information media work. Thus we can try to consider the use of analogy in newspapers, periodicals, radio stations, television stations Using such information will belong to "legal permission" form.

\section{COUNTERMEASURES FOR THE DEVELOPMENT OF DIGITAL LIBRARIES IN CHINA}

\section{A. Analysis Connotation of the Digital Library, Strengthening Quality Training to Staff and Users}

We cannot finish the construction of digital libraries within one night, and we can truly put the theory into the reality and succeed in building digital library entities by having a deeper understanding of the theory of digital libraries to a certain height. The construction of digital libraries is not simply digitalization of books and materials, but it is a process of dealing with the users, the content, the technology and economy. The wider use and deeper application of the digital and network in the library give digital libraries a lot of changes in the form of the work and management. Not only are the users contents consumers but also they are the contents founder and organizer. Digital technology that provides different forms of service will finally give the industry of library a far-reaching influence. Therefore, having high-qualified users will give digital library a decisive impact.

\section{B. To Strengthen the Quality of Training of Staff and Users}

Digital library constructers should know that the digital library is a long time project, which require both high technology and high quality personnel, so that the personnel's constant cultivation will have significant meaning to process of promoting China's digital libraries construction. In personnel training, to select the people who both know technology and information and have profound cultural background will be the most important thing to do. Various means and methods should be employed to broaden the scope of the training, therefore a reasonable plan is the 
first priority, which should contain adjustable short-term, medium-term and long-term goals. Personnel training resources can be from the library's own unit, but it also needs to employ excellent people from outside world. First, in order to fully tap the staff's own potential, long-term training can be based on the unit's local resources: by paring the strong with the weak, by discussing with and complementing each other, it will effectively play teamstrength. Second, in order to broaden their sight, personnel should go out for further education, for the construction of digital libraries should be long-sighted only by going out and accepting new theory, new practice, can staff get their own quality all-round ascension. Third, libraries should add more training funds so that the training wouldn't be closed because of the lack of funds. And the last ${ }^{[5]}$, because the digital library is a relatively new subject, there will definitely be problems from both the theoretical aspect and in the process of materialization. Therefore, it's necessary for the units to organize some experts-on-site training and instruction, which we believe will be really helpful for the staff to have awareness of the digital library in time, so as to strengthen and improve their own quality.

\section{Strategy for Copyright Problems}

During the construction of digital library, proper and reasonable use of the rights imposed in the copyright law should be emphasized. On the one hand, we should start up immediately without hesitation_waiting until the completion of the law that carries on promoting the further improvement of the copyright legislation will be a waste of our valuable time; On the other hand, at the country's legislation level, current law should be continuously adjusted to fit for social development, and in turn, the operation of digital libraries will also promote the copyright legislation perfection.

Moreover, setting up the Internet charging system, we believe, will be the corresponding measures to take to control copyrights management, which requires the users to pay a reasonable amount of fees when they use some digital resources for the author's copyright. The technical copyright protection is through the use of advanced computer technology ${ }^{[6]}$, which will effectively prevent piracy and illegal copying, thus fundamentally promoting the development of the library.

\section{CONCLUSION}

Digital library construction has achieved fruitful results, which drastically meet readers' information needs. At the same time, the diversified services of information resources require further development and follow-up.

\section{REFERENCES}

[1] DAI Lei,SONG Wei,SHI Lin.Cost-benefit Analysis in the Construction of the Digital Library Federation[J] Information Science, 2012, 30 (11): 1677-1680.

[2] Zhu Yaling Li Na. Exploration and Practice of the Digital Library Promotion Project in Providing Regional Digital Cultural Services:A
Case Study of Changchun Digital Library [J] Journal of the National Library of China, 2012, 21 (5): 76-80.

[3] Li Hu Li Xiaoqiang. Construction and Practice of the Digital Library Promotion Project in Shanxi Province $\{\mathrm{J}$ Journal of the National Library of China, 2012, 21 (5): 54-59.

[4] Chen Ye Mi Yongdi Liu Xiaoqing The Digital Library Exploration and Practice in Zhejiang Province. [J] Journal of the National Library of China, 2012, 21 (5): 60-65.

[5] Pan Hui. Research on Project Management in the Digital Library of University [J] Journal of Modern Information, 2010, 30 (5): 30-33.

[6] OUYANG Cai-xin. Probe into the Copyright Problem of the Digital Library [J] Sci-Tech Information Development \& Economy, 2006, 16 (11): 62-63. 